\title{
CDISC SEND Category for Clinical Observation Terminology
}

National Cancer Institute

\section{Source}

National Cancer Institute. CDISC SEND Category for Clinical Observation Terminology. NCI Thesaurus. Code C89963.

The terminology that includes concepts relevant to the Clinical Data Interchange Standards Consortium (CDISC) Standard for the Exchange of Non-clinical Data (SEND) categ ory for clinical observations. 